\title{
How Software Practitioners Use Informal Local Meetups to Share Software Engineering Knowledge
}

\author{
Claire Ingram \\ Anders Drachen \\ claire.ingram@york.ac.uk \\ anders.drachen@york.ac.uk \\ Department of Computer Science, University of York \\ York, UK
}

\begin{abstract}
Informal technology 'meetups' have become an important aspect of the software development community, engaging many thousands of practitioners on a regular basis. However, although local technology meetups are well-attended by developers, little is known about their motivations for participating, the type or usefulness of information that they acquire, and how local meetups might differ from and complement other available communication channels for software engineering information. We interviewed the leaders of technologyoriented Meetup groups, and collected quantitative information via a survey distributed to participants in technology-oriented groups. Our findings suggest that participants in these groups are primarily experienced software practitioners, who use Meetup for staying abreast of new developments, building local networks and achieving transfer of rich tacit knowledge with peers to improve their practice. We also suggest that face to face meetings are useful forums for exchanging tacit knowledge and contextual information needed for software engineering practice.
\end{abstract}

\section{CCS CONCEPTS}

- Information systems $\rightarrow$ Collaborative and social computing systems and tools; Social networking sites; • Social and professional topics $\rightarrow$ Informal education; • Software and its engineering $\rightarrow$ Collaboration in software development.

\section{KEYWORDS}

Informal networks, Meetup, developer communities, knowledge sharing, tacit knowledge

ACM Reference Format:

Claire Ingram and Anders Drachen. 2020. How Software Practitioners Use Informal Local Meetups to Share Software Engineering Knowledge. In ICSE 2020: The 42nd International Conference on Software Engineering, 23-29 May 2020, Seoul, South Korea. ACM, New York, NY, USA, 13 pages. https://doi. org $/ 10.1145 / 3377811.3380333$

\section{INTRODUCTION}

In recent years informal technology meetups have become an important aspect of the software development $[11,62]$ and technology

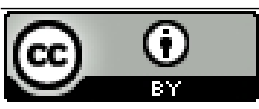

This work is licensed under a Creative Commons Attribution International 4.0 License.

ICSE 2020, 23-29 May 2020, Seoul, Republic of Korea

(c) 2020 Copyright held by the owner/author(s).

ACM ISBN 978-1-4503-7121-6/20/05.

https://doi.org/10.1145/3377811.3380333 startup [43] communities [9, 22, 46]. In the UK, some economic analysts have even begun to use data about technology-oriented meetups as an indicator of the health of the local technology sector (for example, see [7, 16-18, 22, 40, 62, 64]). Many platforms exist to facilitate local technology meetings, collectively termed EventBased Social Networks (EBSNs) [37]. For example, Meetup.com ${ }^{1}$ is estimated to support more than 3,500 local groups in the UK alone, attended by 1.6 million members across 263 locations [62], while EventBrite.com hosted 3.9 million events in 170 countries worldwide in $2018^{2}$. Many of these groups are devoted to technology topics and attended regularly by large numbers of experienced practitioners. Despite this, little is known about participants' motivations for engaging in software-oriented local meetings, what kind of information they obtain and how the growth of such communities might affect software engineering practices.

Previous studies in the field of knowledge management have suggested that software development is heavily reliant on 'synthetic' knowledge [5, 6, 50,67]. Such knowledge is primarily oriented around problem-solving, and tied to practical 'know-how' and understanding of specific applications [71]. It is usually tacitly held and accumulated through experience and 'learning by doing' $[5,6,50]$. Tacit knowledge is not generally secret, and in fact is easily seen through observing experienced practitioners [23, 68]. It is inextricably tied to specific applications [39] as well as a particular person's own working context and mental models [45], and is often taken for granted - making it difficult to codify and therefore to share outside of local contexts [12, 23, 34, 45, 49, 70]. Synchronous, face to face conversations permit rich contextual information to be shared alongside technical information, which in turn aids the surfacing, exposure and transfer of tacit knowledge. Theoretically, therefore, local meetups should be particularly helpful for software engineers as they create such opportunities for face to face discussion.

Our current research aims to understand more about how and why software practitioners participate in local meetings, how face to face meetups complement the existing communications channels available to developers to share knowledge, and whether the regional, informal, face-to-face nature of local meetups allows for exchange of knowledge not otherwise easy to obtain. The research focuses specifically on the local groups facilitated by the Meetup.com platform, the best known EBSN for publicising local technology clubs and meetings. We collected information from the leaders and participants of technology-oriented meetup groups in a variety of

\footnotetext{
www.meetup.com

${ }^{2}$ https://www.eventbrite.com/blog/press/
} 
locations, using mixed methods research techniques to produce rich qualitative data and triangulate it with quantitative survey data.

The rest of this paper is laid out as follows. In Section 2 we summarise what is known about communication channels exploited already by software developers for sharing relevant information. Section 3 introduces our research questions. In Section 4 we explain the research design. Section 5 presents our findings while Section 6 discusses the implications. Section 7 outlines the limitations of our study and Section 8 presents conclusions.

\section{BACKGROUND}

In this section we survey some previous literature on communication and knowledge gathering to support software engineering practice, and survey what little previous work has been conducted on meetups.

\subsection{Event-Based Social Networks}

There has been some limited previous study of EBSNs, social media networks which exist to facilitate meetups, although none has focused on technology-oriented meetups or their potential for knowledge exchange. Ricken et al examined Meetup group organisers' attitudes towards leadership [53] and whether this could be linked to group survival. Liu et al. studied data from Meetup and Gowalla [37], noting strong correlation between users' online and offline networks and interactions. Macedo et al. examined recommender systems for recommending Meetup groups to users [38] while Sander \& Seminar collected information about Meetup participants in general (not restricted to technology-oriented groups), noting that participants tended to be highly qualified [55].

\subsection{Knowledge bases}

Much previous work has been conducted on knowledge exchange in various industries.

The 'knowledge base' theory of knowledge exchange [4-6] characterises the type of knowledge required for a particular activity, the actors involved in transferring and developing it, motivations for knowledge creation, and learning styles [70]. Knowledge management researchers suggest that different industrial sectors rely on different types of 'knowledge base' [5, 6, 70]. Three types have been identified previously. Analytic knowledge [4, 5] underpins scientific advancements. This type of knowledge is highly codified and formally described, and its meaning is close to universal across cultural and regional contexts $[39,44]$ so it is readily exchanged globally [44]. Symbolic knowledge underpins creative and/or intangible products, ideas and experiences, such as art, design and music [4]. It is interpreted within a particular cultural context, tied to a specific region $[26,39,70]$, so knowledge exchange is dependent on geographical co-location. Synthetic knowledge [4, 5] is focused on practical problem-solving. Knowledge is applied and highly specialised, and tends to be tacit, experience-based, difficult to transfer, and connected to a specific problem, challenge or application [39]. Knowledge is accumulated through experience and 'learning by doing' $[4-6,50,71]$. The tacit and highly applied nature of synthetic knowledge makes it difficult to codify and therefore to share outside of local contexts $[49,70]$.
Previous research has suggested that engineering and software development activities are heavily dependent on synthetic knowledge [5, 50,67], which primarily addresses problem-solving. According to this model, software engineers should therefore gain benefit from meeting in informal and face-to-face settings, because this creates opportunities to surface, expose and transfer tacitly-held, experience-based, problem-solving knowledge.

\subsection{Communication channels for problem-solving}

When encountering intractable technical problems during development, software developers exploit a variety of channels to find a solution. This commonly means tracking down some very specific information or experience, acquired either by searching through archives of online material or by identifying a person who holds exactly the right experience. Accessing a large number of people maximises the chances of finding such a person. Common practices include asking (and answering) very specific questions [1] on interactive platforms with large audiences such as Twitter [61], or Stack Overflow [66].

The knowledge base model implies that speaking directly with a knowledgeable person is theoretically an ideal solution for acquiring problem-solving synthetic knowledge. Conversation allows a developer to focus in swiftly on the key information they are currently lacking, and to ask questions to obtain an explanation tailored to their needs. This would suggest that local meetups should be an ideal medium for obtaining the type of problem-solving knowledge that underpins software development. Local meetings could also be useful for building up a personal network of contacts, who might be able to help with solving problems when they arise in the future.

\subsection{Staying up to date}

There are other reasons why meetups might be useful to software engineers. New tools, techniques, frameworks and innovations emerge quickly in the software domain [61] and practitioners need to ensure that their skills do not become obsolete and that they are benefiting from lessons learned by others. Twitter is known to be an important platform for this; news, technical updates and technical discussions are some of the most important categories of tweets for software-oriented users [10, 57, 61, 65, 73].

News aggregation websites are valuable for knowledge sharing [35]. Software developers have two separate goals here: staying up to date with new technologies (e.g., via Hacker News[3, 73]); and learning and improving as a developer (e.g., through blog posts or forums such as Reddit [3]). There can be an almost overwhelming amount of information; prioritising it and reducing the noise can be difficult $[58,61]$. We suggest that local meetups could provide an accessible way to filter out the noise, relying on group discussions to work out what information is likely to be most relevant and important.

\subsection{Networking}

Much of the software development industry is project-oriented. Firms are frequently required to assemble new teams, only to disband the teams once a new product is released. The ability to quickly recruit and assemble new teams is therefore key and project-based 
industries like this rely heavily on the presence of local pools of actors with the relevant experience and skills [8, 14, 20, 27, 48, $56,63,69]$. From the point of view of the individual practitioner, building out a local network can be important for hearing about opportunities.

Going further and engaging actively in local networks as an organiser or presenter at a local meetup allows a practitioner to build a personal reputation for their specialist knowledge and previous achievements, which increases the chances they will be recruited to interesting future projects. There is already evidence that developers use other channels such as Twitter [10, 61, 65] and Reddit [3] to promote their own work and build a reputation, or to share information about jobs [65].

Building up knowledge about potential collaborators and partners in this way has been defined as a type of knowledge coined Know-who. It can be compared to other types of knowledge such as: Know-what (information and factual knowledge); Know-why (social and physical principles and laws); and Know-how (applied skills and capabilities) [39]. We suggest that local meetings can provide a rich environment for acquiring tacit information about individuals, firms and job opportunities in the local region, through informal conversations that can cover information which may never be formally written down.

\subsection{The Meetup platform}

Meetup is a platform for finding and building local communities. As of mid-2019 Meetup has over 44 million members worldwide who can opt to participate in one or more of the 330,000 groups which the platform hosts. Meetup facilitates over 84,000 events every week globally. Although other, similar platforms exist, our research focuses on Meetup.com, as arguably the largest and best-known platform for facilitating local meetings $[53,55]$.

\section{RESEARCH QUESTIONS}

Based on the literature review summarised above, we developed research questions to be addressed. Before collecting data, the lead author attended eight different technology meetup communities as a participant, in cities both inside and outside our selected study regions, and targetting groups with varied topics, formats and sizes. This enabled observations of: typical meeting format; participants' interests; variations across different groups and regions; and groups' relationships with their local area. These observations influenced the framing of our research questions.

Very little is known about why software professionals choose to give up spare time to attend meetups, so our first question aims to address this.

RQ1: What motivates software professionals to participate in technology meetups?

Secondly, little is known about how meetups might affect the practice of professionals who choose to engage, so our second question tackles this subject.

RQ2: How do software professionals make use of information they receive from meetups?

Our literature review identified four potential motivations for meetup participation: solving problems; building contacts for future help; acquiring relevant technology news; and acquiring relevant regional news. Previous research illustrates how developers use various social media and online tools to satisfy many of these motivations. However, it's not clear how face to face local meetups might complement these online activities, or whether developers use local meetings and online tools for different information-seeking purposes. Our final research question aims to address this.

RQ3: Do informal local meetings allow software professionals to access resources (e.g., new knowledge or contacts) that are difficult to access through other means?

\section{RESEARCH METHOD}

It's prohibitively time consuming to attempt to gather data to answer our research questions on a worldwide scale. Instead, we have focused on a single country (UK), employing a mixed methods approach. Our research design is based on the concurrent triangulation design for mixed methods research, as described in [15]. This research design sees two concurrent but separately conducted stages of data collection and analysis: a qualitative stage of collection and analysis; and a separate quantitative stage. After data for each stage has been collected and analysed separately, the two types are compared and combined to produce an integrated conclusion.

Stage one of the research involved qualitative techniques (interviews) to collect data from Meetup group leaders and/or founders. Interviews are a useful tool for collecting rich information which often cannot be obtained using quantitative measures [25]. This also allows us to validate some of the ideas extracted from previous literature as well as to search for newly emerging concepts.

Stage two of the research involved using quantitative techniques (survey) to collect data from Meetup group participants. The population of people participating in (as opposed to leading) meetup groups is very large, meaning that a survey is a reasonable choice. Although the two stages are conducted independently, concepts and vocabulary emerging from the interviews did influence the design of the survey.

Finally, data and conclusions from the two stages were compared.

\subsection{Selecting regions}

Location is likely to be an important factor affecting how Meetup group members interact with their local community, because regions differ in terms of - for example - regional specialisms, relative populations of large, medium, small or micro-businesses and survival rates for technology-oriented firms. Differences like these could result in very different patterns of participation in different locales. We want to reduce the possibility that we inadvertently introduce a bias into our study through selection of location, and therefore we selected five separate locations for our study, which together present a diverse set of regions. To select these regions, we built on previous research conducted by the UK-based innovation charity NESTA $^{3}$, which has analysed economic data (and statistics from Meetup) to identify almost 50 regional clusters in the UK which are strong in creative industries like software development [16]. Using the same data, NESTA researchers divided these clusters into five different cluster types, giving examples of each. We selected five of these example cities, each one representing a

\footnotetext{
${ }^{3}$ https://www.nesta.org.uk/
} 
different type of cluster. The cluster types [18] (and our selected example cities) are as follows:

- Creative districts are dominated by a diverse range of creative micro-businesses with few high-growth firms. We selected as an example Brighton, in the south east of England

- Creative conurbations have high survival rates for creative and technical firms, relying on high-growth firms for job creation more than other types of clusters. As an example, we selected Peterborough, which is in the UK's east midlands

- Creative capitals feature large and medium creative firms and a relatively high proportion of high growth businesses. We selected Glasgow as an example, the largest city in Scotland

- Creative challengers are relatively young clusters, with diverse business ecosystems and some high growth firms. We selected Newcastle in the north east of England

- Incipient clusters are recently emerging clusters, with as yet relatively low business survival rates. We use Liverpool, a city in the north west of England, as an example

The selected cities vary in size and in industrial specialism as well as location. Selection of a diverse range of cities to form our dataset allows us to avoid introducing regional biases into our analysis of meeting networking patterns.

\subsection{Identifying the population}

We obtained a list of local Meetup groups for each city. Data was extracted between May and June 2019 using Meetup's API console $^{4}$. For each selected city, we obtained a list of all groups located within 25 miles, limiting the search to groups classified with the topic 'Technology'. We also extracted data about these groups' recent activities, including the number of meetings that each group had successfully hosted in the previous 12 months and the total number of Meetup members for each group. This initial list included 255 technology groups in total. Our study focuses on active meetup groups, so we eliminated all those groups which had not successfully held an event in the prior twelve months. If a group had scheduled an event and subsequently cancelled it we did not count this as having successfully held an event. The new list of active groups totaled 152 groups across all five regions.

We wished to study Meetup communities specifically relevant to software professionals and we therefore eliminated groups from our list which are not. To achieve this, we looked at each group's published topic classifications, read their descriptions and scanned the agenda of recent meetings. Groups were eliminated only in cases where we could not find evidence that their interests included aspects of software development, and we could not find evidence that meetings included content relevant to software development. The following groups were excluded: Brighton SalesForce User Group; YouTube Creators in Liverpool; Glasgow ServiceNow FoCus Community Meetup; Brighton Podcasting Meetup Group; T-shaped Talks (Brighton); Glasgow Coworking; The Happy Startup School Brighton; Cambridge Social Media Club; and \#ShakeItHUB Design and Marketing.

The new list consisted of 143 active groups, which formed our total population of active Meetup groups relevant to software professionals. The complete list of all groups in our study population is

\footnotetext{
${ }^{4}$ https://secure.meetup.com/meetup_api/console/
}

included in Appendix D [28]. Group interests were varied, including groups holding mixers designed to stimulate new ideas for software products, and groups for CTOs and technology startups, as well as groups dedicated to business analysis, general software development, agile projects, mobile and web technologies, blockchain, bitcoin, cyber-security, SEO, ecommerce and testing. The most popular topics were: programming and general software development (45 groups specialised in these); data science, $\mathrm{AI}$ and/or machine learning (18 groups); and aspects of cloud computing (11 groups).

We are interested in how individual software development practitioners engage with their local community, and so our unit of analysis for this study is the individual practitioner.

\subsection{Interviews}

To understand the motivations and perceptions of Meetup group organisers, we conducted semi-structured interviews. This format encourages interviewees to freely share their thoughts, while researchers can follow up interesting emerging topics [25]. We randomly selected one third of the active groups in each city, contacted the group leaders and invited them to participate in an interview. In total we contacted 48 group organisers. Twelve group organisers responded and agreed to be interviewed (a response rate of $25 \%$ ). In total we interviewed the leaders of $8 \%$ of the total population. The interview guide for the semi-structured interviews is included in Appendix A [28]. At the conclusion of the 12 interviews, we felt that saturation had been found, with each new interviewee largely confirming previous observations. All interviewees worked in the fields relevant to the Meetup groups they ran. Groups spanned a range of topics and group sizes, broadly reflective of the overall population.

At the start of each interview, we explained our research goal and obtained permission to record and transcribe it. Five interviews were conducted as video conference calls, and seven as voice calls. One researcher conducted all the interviews. Interview duration varied from 25 minutes to 1 hour 5 minutes. Our interview guide focused on four main topics: (1) how the interviewee came to be involved in the group and what their goals were in creating/running it; (2) why meeting face to face was useful for those goals; (3) whether and how they had used information gathered from Meetups; (4) major challenges involved in running a meetup group. Interview recordings were transcribed and coded using NVivo software. Initial open coding was conducted using a priori codes shown in Appendix C [28]. A priori codes were derived following literature survey and informal discussions with participants at meetups both inside and outside our target cities. We attached a priori codes to relevant information in the transcripts. During analysis new concepts emerged which were not accounted for by a priori codes, and these were added to the code book as emergent codes (also listed in Appendix C). These codes were then studied and grouped into further categories, which are reflected in Sections 5 and 6.

\subsection{Survey}

We designed a survey to distribute to group members. This allowed us to triangulate findings from interviews, as well as collect inputs from a wide body of participants. We included a description of the aims of the research project, and then asked respondents to indicate 
their agreement with statements which were derived from the combined literature review and interview analysis. These included: motivations for participating; what they liked about a face to face meeting; and what they thought worked well in meetings. There were 30 statements to consider, and answer options ranged from strongly disagree to strongly agree, in a 5-point Likert scale. We also asked respondents to indicate whether and how they had used information they had learned at a meetup, or whether and why they had got in touch with someone they met at a technology-oriented meetup. Finally, we captured the location where they attended meetups, whether they worked in a relevant role and how much experience they had. The estimated time to complete the survey was 5-10 minutes. The full survey is included in Appendix B [28].

The survey was distributed to participants of 15 randomly-selected Meetup groups drawn from our population, which had not previously been contacted with an interview request. The survey was promoted through public discussion boards on a group's Meetup homepage, or through a group's dedicated Facebook page, Twitter account or Slack channel. We also promoted the survey link generally on Twitter, in city-specific Slack channels, and city-specific subreddits on Reddit, making clear each time that we were searching for people who attended technology-oriented meetups in a specific city. Questions capturing the region where a person attended technology meetups were used to screen out responses from outside our target areas.

In total we received 87 responses. In cleaning the data, we subsequently removed 13 responses. One respondent selected an option indicating they had never attended a meetup in any of our target cities. One respondent had not accepted to enter their responses into our research program (a mandatory requirement for our survey). And 10 respondents returned completely blank questionnaires, recording no data. Our final total therefore was 74 .

\section{FINDINGS}

In this section we present the results of interviews with group organisers and survey of group participants.

\subsection{Characteristics of the respondents}

Here we characterise the respondents to our survey.

We asked survey respondents about the relationship between their current work and their attendance at the meetup. Sixty-seven respondents stated that they currently work in technology (90.5\%). One respondent was a student studying technology, two people are not working in technology but thought that the topic was useful for their own career development, and four declined to answer the question.

Next, we asked how long have they been working in technology? Survey results suggest that meetup participants are distributed across different experience levels, with $36.4 \%$ of survey respondents having 10 years or fewer of industrial experience, and a similar proportion (33.7\%) having 11-20 years of experience. Overall, a majority (58\%) of respondents claim at least 10 years of experience working in technology, and $24 \%$ more than 20 years of experience. Based on our survey sample, we suggest that meetup communities tend to be relatively experienced, but that early careers participants form a sizeable minority.

\subsection{What motivates software professionals to participate? (RQ1)}

We asked our interviewees to describe their motivations for founding a new group, or becoming part of the leadership team. We also asked them what they believed motivated their group members to come along. And, separately, we asked survey respondents what motivated them to get involved as group participants.

5. .12 What motivates group organisers? The interviews with group organisers revealed varied reasons for leading Meetup groups, and naturally most group leaders had more than one reason. A common theme was a desire to make friends with technical interests. The importance of a social atmosphere for meeting people with similar roles became a major theme throughout the research, raised by most interviewees in various forms and by many survey respondents. We discuss this further in Section 6. "They posted a thing on GitHub, which was like "Developers near you", or something. And there was like ... 3 accounts on GitHub which were near [...]. So I was like, "Oh ...This is amazing!" So we got chatting on Twitter. And I was like, "Yeah, we should start a meetup"' Three interviewees had consciously used Meetup to find people after moving into their region: 'But, moving away and then coming back, I was like "How do I meet people again?" So that was a good way of introducing myself and my skills to people. So yeah, that's probably.... I've probably used it to make friends and a network as much as anything else, yeah.' Three other interviewees had founded groups after attending meetings in other regions and realising there was nothing similar near to home.

Although none of the interviewees worked specifically in recruitment, four group founders mentioned that they had started a meetup community partially to help with recruitment to their team or firm. In one case the group founder saw the community as an important and welcoming forum for encouraging young practitioners or career changers to enter their specialist field, which has a shortage of qualified personnel.

Personal passion for technology is an important motivating factor. For example, two of the interviewees had got involved in their respective meetup communities partly to evangelise about their favourite aspect of technology: 'That's my own personal plan, to try and encourage open source technologies.' Two separate interviewees explained that they wanted to explore an exciting and interesting new technology themselves: 'It's cool, interesting new tech. So, a couple of us were like, "Oh, we should get together, and sort of have a meetup about that". Because it's way for us to explore it, or tell other people about it. And so we started... yeah, we started that meetup which was the kind of start of finding a community.'

Three of our interviewees were partially motivated by a deliberate desire to stretch themselves, particularly to improve confidence at public speaking.

Assuming the group can be successfully built up, running a community can be a useful tool for building a reputation, which can be very helpful for long-term career goals. 'And it's building your own brand, really. It comes back to that [...] so people knew what I was doing.'

The effort involved in building up a successful group should not be underestimated; 5 interviewees expressed that sometimes the effort involved could be discouraging. Having a personal passion for the topic, or for the community itself, was an important motivator 
What motivates you to attend a technology-oriented meetup?

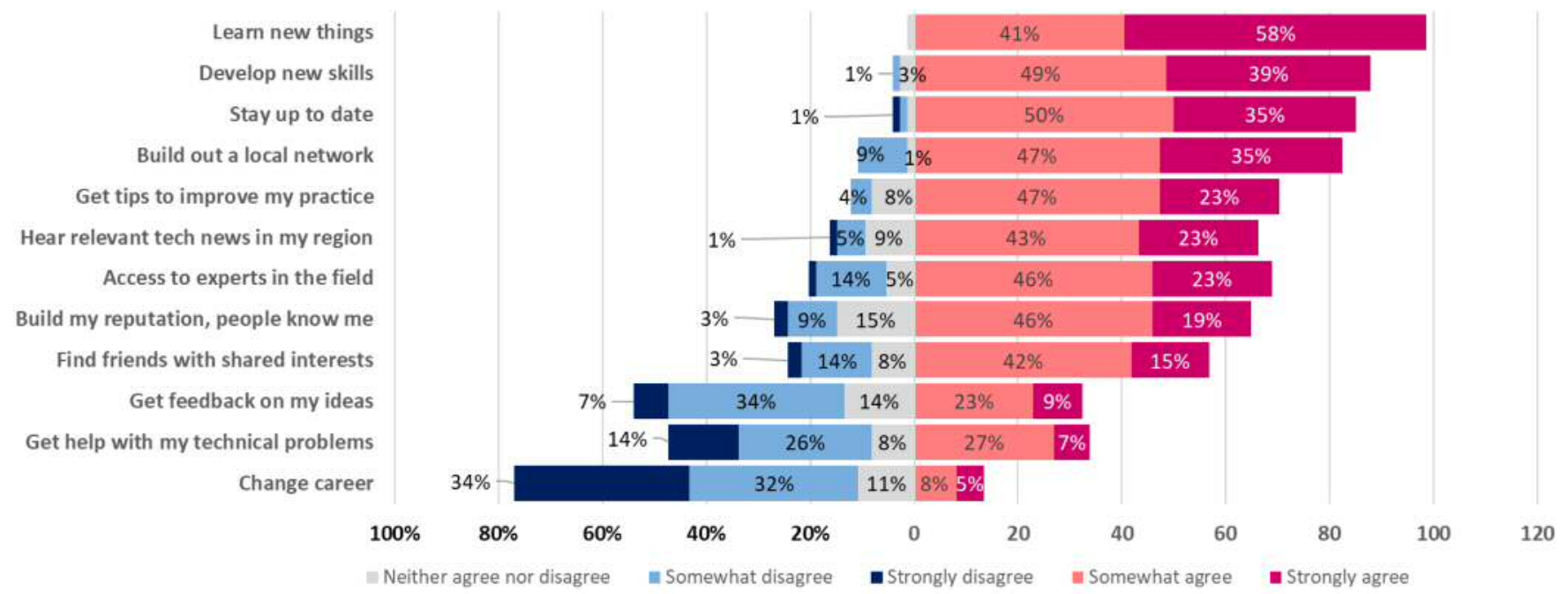

Figure 1: Stacked bar chart illustrating motivations to join to technology-oriented Meetup group

for many of the group leaders; without this, it's clearly difficult to push a new group through the challenging first few years. The two biggest issues for our group leaders were the difficulty of providing a constant flow of new content and/or speakers; and finding a venue that has the right facilities, and is accessible, affordable and reachable. Each of these issues was raised by 9 of the 12 interviewees. Being region-specific, the presence or absence of certain key local facilities suitable for meetup communities might adversely affect specific locales. For example, almost all the interviewees from one region raised the recent closure of a specific space which had previously been readily available for evening meetups. Across all our regions, many groups are reliant on a local sponsor which is prepared to offer their own space, or funding for one. Other difficulties also mentioned by group leaders included unpredictable attendance (there's usually no penalty for failing to attend) which was mentioned by 6 interviewees, as well as the difficulties involved in: converting occasional participants into a regular community (5 interviewees); promoting the group (5 interviewees); ensuring high quality content without sales pitches ( 5 interviewees); getting the meeting start time right (3 interviewees); finding a diverse range of speakers, particularly women speakers (2 interviewees); and encouraging debates and organic discussions around a talk (2 interviewees).

5. . 2 What motivates participants? Survey participants were asked to rate their agreement with some statements about potential motivations, using a five-point Likert scale (Strongly disagree, disagree, neither agree nor disagree, agree and strongly agree).

In Figure 1 we present the results, showing percentages of respondents answering with a particular category. We did not force responses for these questions and so some respondents have skipped occasional statements without giving an answer. Consequently results do not total $100 \%$ for all statements. Although most of our suggested reasons to participate get some agreement, the theme of learning new things, developing new skills and staying up to date are ranked by respondents at the top of the list with the highest levels of strong or moderate agreement, along with building out a network.

Survey respondents were offered an optional text field to add additional comments explaining their motivations. Comments fell into the following categories:

- Socialising in a friendly setting (8 people explicitly mentioned this)

- Getting exposure to new people and new ideas, discussions leading to idea generation ( 5 people)

- Keeping up to date (5 people)

- Teaching others, welcoming newcomers and sharing knowledge (5 people)

- Looking for new work or contracts, improving employment opportunities (3 people)

- Getting practice at presenting (2 people)

One respondent mentioned the usefulness of the informed feedback that can be obtained at a meetup, and that the meetup provided a friendly space to share ideas. Another respondent emphasised that understanding other people's work helped them reflect on their own practice. We return to these themes in Section 5.4.

\subsection{How do software professionals use information from meetups? (RQ2)}

Our second research question considers how software professionals use the information they gather at meetups. To answer this question we asked interviewees and survey respondents:

- Have you ever contacted anyone after meeting them at a meetup?

- Have you ever applied things that you've learned at a technologyoriented meetup?

5.3.1 Contacting people after a meetup. Figure 2 shows responses received from the survey respondents when asked if they had ever 
contacted anyone as a result of a meetup. Respondents could select as many reasons as they liked (except for 'no', which was an exclusive option). A few respondents declined to answer. Just over $75 \%$ of all survey respondents have contacted someone after meeting them at a meetup. This is consistent with other studies of Meetup (although not restricted to technology groups), which also found high rates of interaction after meetings [55]. As one interviewee explained, having met someone already makes it easier to get in touch: 'It gives you that kind of personal contact, where you know you can reach out to people once you've met them and you've got that rapport, you can reach out direct to them.'

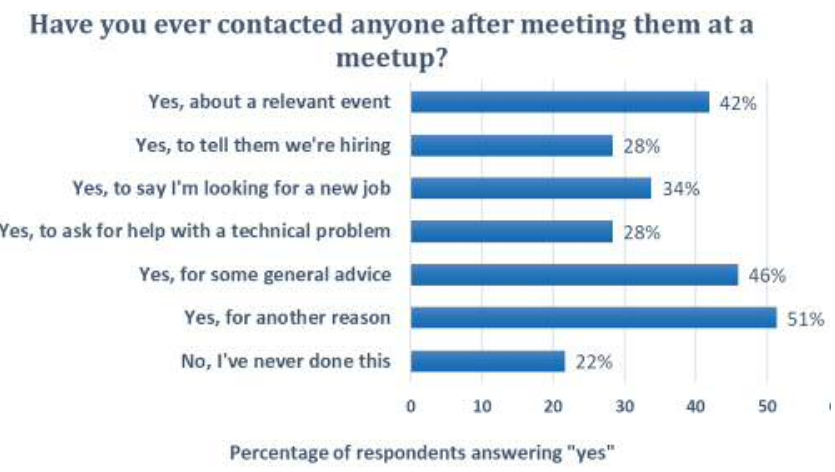

Figure 2: Bar chart showing percentage of respondents who have contacted someone after a meetup

In Section 2 we discussed how local meetings could be a useful forum to find contacts who might be able to offer problem-solving help. This is based on the implications of the knowledge base model, which asserts that software development is mainly underpinned by problem-solving, synthetic knowledge. There is an element of seeking help for problem-solving: $28 \%$ of respondents have contacted someone they met at a meetup to ask for help with a technical problem. However, this is the least common of our suggested reasons for contacting someone.

There is also an element of looking for or disseminating information about local jobs. Several interviewees gave examples of meeting people at a meetup and subsequently working with them, either through hearing about a job opportunity, or by disseminating information about vacancies themselves. One interviewee wrote recommendations for particularly impressive friends acquired from meetups.

Survey respondents were able to provide more information via an optional text box. Comments fell into the following categories:

- For social reasons, to make a friend (8 people - over $10 \%$ of the total population of survey respondents)

- To offer help (5 people)

- To discuss future meetup events (5 people)

- To connect on social media (3 people)

- To follow up on work related contact (4 people)

- To discuss other events (2 people)

- To ask for additional information following an interesting talk or discussion (2 people)

Socialising is a strong message again; we return to this in Section 6.
5.3. Dbtaining new knowledge from a meetup. Figure 3 shows responses received from the survey respondents when asked if they had ever applied some new knowledge to their work after a meetup. Respondents were offered some choices and could select more than one (except for 'no', which was an exclusive option), or they could skip the question. They were also offered an optional field for other suggestions.

Have you ever applied some knowledge that you've learned at a technology-oriented meetup?

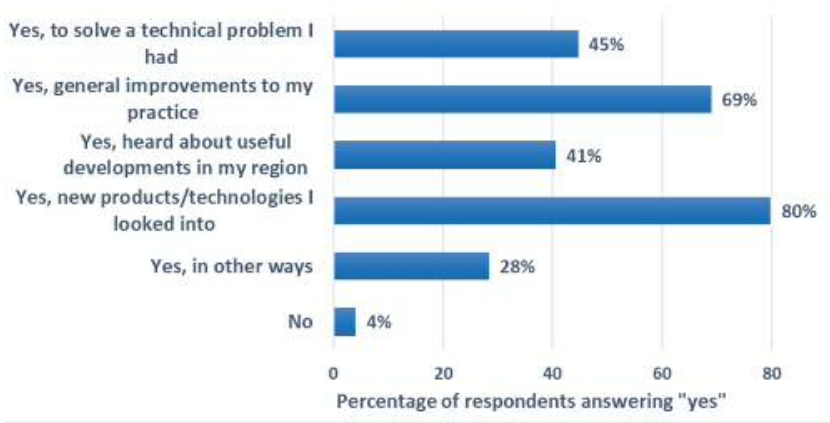

Figure 3: Bar chart showing percentage of respondents who have applied knowledge they learned from a meetup

A majority of respondents have acquired knowledge about new technologies or news that prompted them to take further action $(80 \%)$, or learned something that resulted in improvements to their practice (69\%). Respondents also suggested other ways in which they had used new information from meetups. These included:

- Disseminating new information to other communities (3 people)

- Improving their own communications (2 people)

- Generating new ideas or initiating strategic side projects (2 people)

- Making sales or obtaining work (1 person)

- Personal career development (1 person)

Almost all interviewees also stated that they learned something new at most meetings: 'So in terms of things that I've applied, yes there are tips that I've picked up from every one that I've been to. And I'll then go back and revisit some work I've done at work and see how I can work that new tip into it, to make it better.'

Conversations with interviewees suggest that meetups are capable of fielding discussions that can produce rich, contextualized information that draws on relevant practical experience (the relatively experienced audience is a benefit here). One interviewee provided an example of improving practice following a meetup: It's just different ways of doing things, you know, like elaborating requirements [...] Based on conversations at [the meetup], we've seen how people have reduced the, kind of, wasted effort in developing the wrong requirements. So, as I say, we've taken those on board and adapted things and had success with them [...] And we may well not have gone down that route had we not had that discussion at [the meetup].' 


\subsection{Do meetups allow software professionals to access resources that are difficult to access through other means? (RQ3)}

Interview participants were asked to reflect on why meeting face to face was a good format for satisfying the motivations they had identified earlier, and whether they thought in person conversations offered something they didn't get via other channels. Survey participants were asked to rate their agreement with some statements about meeting face to face, using a five-point Likert scale. Each statement was optional, meaning that respondents were not forced to provide a rating for every statement. They were also offered an optional free text field to provide more details. In Figure 4 we show the results.

Several interviewees pointed out the importance of having a diverse range of people in the room to participate in a conversation, which improved creativity and the quality of ideas. 'If you're just having a conversation, I think people come up with ideas, just off, kind of, waffling on for a bit. Oh, you know - I've thought about this, you've thought about that. And then also I think there's something in having a collaborative answer to a question [...] If you've got lots of different people having that same conversation, you'll also come up with different ideas and different suggestions. [...] there's definite value in everyone coming to the table with different experience, different way of doing things to be able to help people. So having that face to face, you wouldn't get that in any digital, I don't think.'

Another interviewer commented: 'It's how we get more interesting stuff coming out of anywhere, sort of thing. Like, you end up with better ideas, and different ideas and newer ideas, the more kind of perspectives you have on things.'

Survey respondents agreed with interviewees; $70 \%$ of respondents agreed that meeting in person was good for generating new ideas. This principle has also been thoroughly evidenced in previous research. People tend to generate ideas from the pool of information or knowledge to which they have access; presenting a wider pool of knowledge can therefore stimulate new directions [47, 60]. Numerous previous studies have found evidence that bringing in a more diverse range of perspectives results in better innovation. For example, more heterogeneous SME management teams [30, 51], diverse knowledge bases [21] and divergent thinking [19] have all been linked to firm growth. Similarly, collaborating with more partners which are different to ourselves or to each other can result in more innovative products $[13,31]$ or increased innovation output $[24,33]$. A meetup provides an excellent potential forum for this type of exchange, because face to face interactions permit rich, context-ranging conversations upon which idea generation often depends.

Eighty-nine percent of respondents agreed that conversation in person was a faster way to obtain information. One respondent added a comment to explain that this is because because the searcher is often not even asking the correct question. This suggests that their mental model of the problem and its context contains some errors. Previous research has suggested that software engineers need to be able to indulge in discussion with social interaction to resolve misunderstandings like these, and establish a common frame of reference [32]. This point is further supported by comments from interviewees: 'Fust to be able to have a conversation about it, rather than, you know, just a very tunnelled, back and forth online. Because, you know, conversations lead from one point to another, they're a lot broader [...] you can then expand that, because then in that conversation people might talk about how that's related to something else and it gives you new ideas for your future projects.'

'Tunnelled' conversations are a feature of technical discussions via mediums such as Twitter or Stack Exchange, where developers are frequently searching for a very specific piece of information [1]. The time-consuming and asynchronous nature of written communications tends to mean that conversations are to the point and disinclined to range around a topic (and are sometimes constrained in length, as on Twitter). They are also likely to pause or stop abruptly. Reflecting on this contrast, one interviewee said: 'Most people that I've met online, there's nothing that commits them to a community. They.. they come and go. Yeah... face to face meetups... also the expectation to meet semi-regularly, it's something that fosters relationships, I think.'

Survey respondents also generally agreed that they could hear information not otherwise available. Interviewees touched on the fact that talking to others with similar roles about their experience and their work allowed them to share tacit knowledge which is not normally written down (the same point was made by three survey respondents). For example, one interviewee said: 'having that interactivity is important so you can say, "I don't understand that bit" and you can actually have a discussion that leads to, you know, better understanding for everyone [...] you definitely get to hear more things... and maybe that's a reason why it's useful to have the people there [...] Because you'll get little bits of information and people share kind of... their... I suppose, their experiences with things. And some of that is stuff that they wouldn't necessarily write down. It's about asking the right question and then: "Oh, yeah! But there's this, and this, and you need to watch out for this thing, yeah, and I had this problem using this bit of software..." And it's not something you'd necessarily think to write down, to begin with, but you definitely get that kind of cross pollination. Yeah. More folk learning, or something.'

Several interviewees suggested that many practitioners might exchange tidbits in person that they would not want to broadcast more widely: 'I think no one's ever going to give their top secret, super duper secrets away on a blog. Because they want it to become a oneto-one conversation.' Talking in person allows participants to build credibility and a rapport before parting with valuable information.

A common theme which was echoed by many interviewers was an emphasis on hearing 'narratives', 'stories' or experiences from people with a similar job: 'I'd like to do more of the story telling a bit. It grabs people's attention a little bit more and helps it relate to them.' Multiple organisers pointed out that 'story' type speakers, talking through a project or case study, can provide useful material: 'You also learn stuff, you learn good stuff while you're there. You learn from the sessions. You hear other people's stories [...] from the angle of an engineer: this is how we set it up, this is how we overcome challenges. That's the stuff that I want [...] real-world stuff, [...] stuff that everyone's experienced, and the challenges that they'd overcome and that he engineered and that sort of stuff. That's the stuff that people want to hear.'

Previous work studying communities of practice has identified story-telling and narrative as an important aspect of learning [12]. Presenting a story (e.g., recounting how some new technology 
What are the advantages of meeting face-to-face in person to discuss technology?

Conversation in person a fast way to get information

Easier to generate new ideas talking in person

Talking to other people with similar jobs reassures me

Get to hear things not usually in tech news

Helps me identify most important industry developments

Can ask questions, get answers tailored to me

Important to feel part of a community

Good way to make friends

Build a network I can reach out to if I have problems $12 \%$.

$40 \%$
$1 \%-11 \% \quad 5 \%$

$53 \%$ $19 \%$

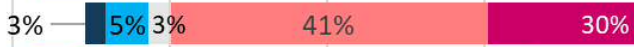

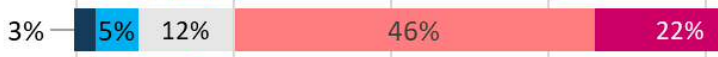

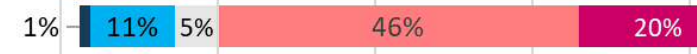
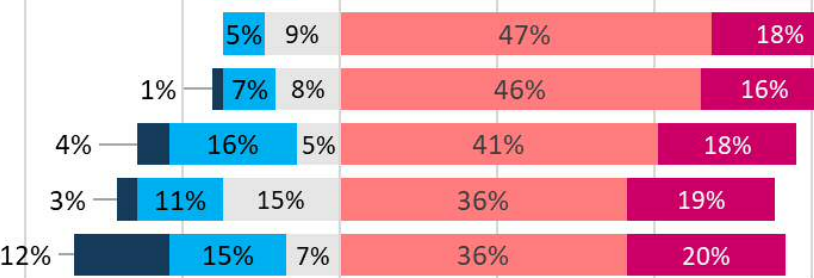

$20 \% \quad 0$

20

40

60

- Somewhat agree

- Strongly agree

\section{Figure 4: Stacked bar chart showing what respondents liked about meeting face to face}

was deployed as part of a solution, a common topic for a meetup presentation) can be useful for imparting technical information which is at the same embedded in rich contextual detail about the specifics of the problem domain, team dynamics, or new things that had to be learned. 'Reminding ourselves how we do things' allows us to focus on important details and distinctions that we often miss [68]; listening to others talk about work similar to our own is a way of doing this. Two interviewees additionally pointed out that it was important to ensure presentations contained quality information and were not sales pitches for the presenter: '...you're asking people to try and take their own personal time [...] they don't want to sit and hear a sales pitch, really. Especially if it's a product that doesn't help them, or, you know, doesn't help them in their job [...] they might not have any say on what sort of product the company uses or anything... they just want to hear about the tech, really, I find.'

Storytelling can be a useful tool for surfacing and exposing context information and therefore some tacit knowledge. One interviewee gave an example of how and why context can be shared - by talking to peers working on similar tasks in very different environments and organisations: 'A lot of the challenges that we face are actually quite similar, so, it's really interesting to ask a question "how do you do this" to people who work in such different environments [...] Someone described it as kind of sharing war stories.' Most participants are experienced and well-versed in the background already: 'Most of the people that attend have read all the [...] guides and the blog posts and things like that. And they'll know the theory very well. But as I say, just sometimes, how do you implement things [...] in reality, often [there may be] compromises, and how do you tackle that? [...] The reality is often very different. And so it's just about how do people get round that kind of problem in their organisation?'

In this context, one of the most important roles for these types of stories and experience reports was to provide reassurance; more than $66 \%$ of all survey respondents agreed that it was reassuring to hear about others' work. Several interviewees also raised this: 'So a lot of the time, it might just be either reassuring things that I know, and saying, "Yep, okay, that's really a thing." And knowing that what you're doing is right, and everyone else is doing that as well. And it means that, you know, if you're all heading in the same direction, you must all be right.' One interviewee pointed to the isolation that some professionals can experience, especially if they are the only specialist in the firm. Meetups can become an important mechanism for combating this, by providing friendly contacts who have similar jobs. 'Sometimes blog posts and such are all well and good, but you want to hear.. you want to question perhaps more than most people do. There's probably only a couple of occasions where I've read a blog post and actually hit the "reply" button underneath and actually asked a question, and suchlike. Whereas, you know, I think I've learned a lot more in terms of you know having... sitting down and having a face to face conversation where you can drill in to what they're saying a little bit more, and kind of challenge, so... yeah, I think that kind of resource, of people outside your immediate environment, is very useful.'

The question of whether face to face meetups offer information which is not available elsewhere is a complex question. We suggest that they do, and it complements other channels of communication widely used by developers. Bringing people together increases the chances of interesting ideas arising; the nature of in-person conversation facilitates this because it ranges around topics easily. Meeting people repeatedly allows trust to develop, and for practitioners to pool their shared experience and draw on it jointly. In-depth discussions and storytelling increase the chances of tacitly-held contextual knowledge being surfaced and eventually transferred.

\section{DISCUSSION}

In Section 2.3, after considering the knowledge base model, we suggested that developers often require some very specific knowledge to solve technical problems, and meetups could potentially be an ideal form for obtaining this. 
Getting help with problems is an element of a meetup for many. For example, $28 \%$ of survey respondents contacted someone to ask for help following a meetup, while $32 \%$ agreed it was a motivation to attend. Despite this, problem-solving was one of the least important motivations for participating, and was also the least common reason for contacting someone. On the other hand, building up a network is important; $75 \%$ of respondents have contacted someone following a meetup, and $73 \%$ agreed that building out a network was an important motivation. One survey respondent commented that networks were important, but were not for technical problems. Instead, the network was a channel for hearing about or publicising job vacancies, and for obtaining connections that might lead to new customers, suppliers or publicity opportunities.

Meetups create new opportunities for face to face interaction. Face to face interactions are almost unique in supporting 'social presence' $[2,59]$ which can't be conveyed through other media $[2,32]$. Previous research suggests that synthetic knowledge $[5,6$, $50,67]$ is often tied to location because it is developed through experience, closely tied to specific applications and environments and relies on the holder's own mental models [12, 23, 34, 39, 45, 49, 70]. Tacit knowledge is most easily shared when co-located [45]. Our interviewees provided several examples of tacit, practice-based information they had acquired from meetups, including: reducing waste through better elaboration of requirements; identifying and presenting key information to senior people; improving business analysis and requirements elicitation through emphasising open-ended questioning; and how to work effectively in agile teams that have different structures or roles. Meetups support rich, wide-ranging conversations that enable developers to hear multiple perspectives embedded in contextual data, identify where they hold inaccurate mental models, and to re-evaluate and extend them based on new information. This type of knowledge exchange is more likely to lead to general practice improvements rather than resolving technical issues (which does happen more commonly than problem-solving see Figure 3).

We suggest that our initial assumption that software engineering face to face meetings primarily facilitate exchange of technical problem-solving knowledge is not accurate. Previous research suggests that developers do focus in on very specific questions to solve problems [1], but that they use other media (e.g., social media such as Twitter [61] or Slack, or forums such as Reddit or Stack Exchange [66]) for this purpose. We observe that, depending on the nature of the problem, technical and problem-solving knowledge can commonly be codified using well-defined vocabulary for specific computing platforms, operating systems and languages which enables a developer to obtain extremely specific answers to queries by broadcasting to a large potential audience via online tools. In fact, some researchers have suggested that Twitter (and similar archives of questions and answers) has an important role for making this type of problem-solving and implicit knowledge visible [72]. Our research does support the notion that meetups are, for many participants, a good forum for sharing their experiencebased knowledge, and that they are able to share this knowledge because they are co-located and able to discuss in depth. However, the knowledge they share and acquire is mostly not about technical problem-solving.
Face to face interactions also make it easier to develop trust [29]. Trustworthiness can be formed based on 'rational' assessments of a person, such as their reliability, qualifications [36, 42, 52] or competence [41]. Or it may be formed based on emotional and social ties between individuals $[42,52]$. Trust between co-workers can be increased when personal information is shared [54]. Comments made by interviewees and survey respondents would appear to support this: many interviewees emphasised the importance of friendships and socialising alongside technical contacts: I guess the reason I originally signed up was more social than anything else. Increase my circle of geek friends! [...] a lot of the friends I do have are in IT, but they're not necessarily geeks, or someone who wants to pursue it outside of work.' Furthermore, more than $10 \%$ of the survey respondents wrote this as a motivation for participating, and a similar number as a reason for contacting someone after a meetup. Many emphasised strongly the value of developing a rapport that is both friendly and also technical; the community socialises together but also shares knowledge which they then (often) take away and put into practice.

In Section 2.4 we suggested that meetings could be means of staying up to date. There's evidence that this is true. Over $70 \%$ of survey respondents agreed that staying up to date was one of the most important reasons to attend (along with developing new skills and learning new things). $80 \%$ of respondents heard about new products or technologies at a meetup that they followed up on subsequently. And almost $65 \%$ of respondents agreed that meetup communities could help them identify the most important industry developments (see Figure 4).

In Section 2.5 we suggested that local meetings might be a forum for developers to uncover local information (e.g. about jobs) and to build up a personal reputation. Over $50 \%$ of respondents agreed that building one's reputation was an important motivation, and several group leaders mentioned this as a motivation to start a group, but this is not as important for most participants as other factors. Uncovering tacit information seems to be more important. Interviewees provided examples of complex and applied knowledge about software engineering practice that they had collected, including simply hearing the challenges that others faced in their daily work, while $66 \%$ of survey respondents agreed that hearing news was a useful feature of local meeting.

\section{LIMITATIONS}

We employed a mixture of research methods to answer our research questions. We believe that we achieved saturation; interview data and survey results largely corroborated each other. However, all interview and survey participants were self-selected individuals within the respective target populations and it's possible that individuals who did not accept our invitations to participate may have supplied different perspectives, which is a possible source of bias.

Our study only examines positive factors which motivate participants and group leaders to participate; it does not examine motivations or experiences of software engineering professionals who choose not to engage with meetups. The framing of our research questions was influenced by informal discussions with meetup group participants both before and during the study, who 
experience positive 'pull' to participate in meetings, and simply stop attending if they do not find value in the experience.

The most likely additional sources of bias are: obtaining results from a single locations (results would disproportionately reflect regional concerns); or obtaining results from groups which are not diverse in terms of interests or size. To mitigate this, we tried to ensure that interviewees reflected diverse range of locations, topics, and group sizes. Interviewees did represent a broad and balanced spread of technology topics and group sizes. However, they were less diverse in terms of location. Newcastle yielded many more interview acceptances than other locations, producing six interviewees. Therefore it's possible that interview conclusions are influenced disproportionately by concerns and experiences from the Newcastle area. We mitigate this risk by triangulating with interviews from other locations and with survey data. Survey responses were received from all five locations, although fewer than expected from Liverpool. We received approximately 1 survey response for every 3 technology-oriented Meetup groups in the Liverpool area. In other locations we received an average of 1 survey response for every 1.5 Meetup groups.

We recruited our study population via a single platform (Meetup. com) which may reduce the generalization of our results. Despite this, many of our interviewees have participated in multiple communities, and their comments referenced this other experience.

We have explicitly excluded inactive groups from our analysis, so our study does not reflect the experiences or challenges of groups which are dormant or have struggled. Examining how and why emergent meetup communities disappear could form a useful topic for future work. Finally, we deliberately selected locations which have been previously identified as technology hubs. Selecting more rural regions where developers are distributed across smaller urban centres may reveal different data.

\section{CONCLUSIONS AND FURTHER WORK}

In this paper we examined the rapidly growing phenomenon of meetup communities of software developers. Whilst similar communities have existed for many years (e.g., Linux user groups), there has been significant recent growth in group number and specialisation. We collected data to answer some initial research questions aimed at improving our understanding of these communities and what they offer to software developers. Technology meetups are dominated by relatively experienced professionals, motivated by the desire to learn new things, develop new skills, stay up to date and build a local network. Almost all our respondents and interviewees claimed that they had obtained new information at meetup which they followed up later (new tools and technologies, and tips for improving practice) and three quarters had contacted someone following a meetup. Face to face local meetings deliver information that experienced practitioners clearly find valuable.

Conversing in person - particularly if meeting up regularly - allows trust to develop and makes it easier to share information that might be too valuable to publish online. Face to face conversations support surfacing and transfer of tacit information rich with contextual details, which might not seem worth writing down but which is useful to peers, such as approaches to solving daily challenges. Meeting peers with similar challenges to oneself provides many practitioners with reassurance about their own practice, and that the challenges they experience are common elsewhere. Meeting face to face also allows participants to draw on a much larger pool of ideas.

We started our study using an existing model of knowledge exchange which posited that software development, like engineering, is underpinned by synthetic knowledge, which is focused on problem-solving, is application-specific, tacitly-held, difficult to surface and share, and built up through experience. We suggested that meetups should be ideal forums for surfacing and sharing such information. Our findings, combined with previous research, suggest that software developers actively seek two types of information: technical information for low-level problem-solving, which they acquire through broadcasting specific requests for help to online communities; and more rich, context-specific information that spans a range of software engineering skills (such as running agile teams or requirements engineering), which they acquire through participating in discussions and face-to-face talks with other experienced professionals, in forums such as local meetups. This suggests that the model of software engineering as underpinned by 'synthetic' problem-solving knowledge may need to be refined. Problem-solving that requires co-location is more likely to be open-ended, addressing complex problems, rather than closed and technical problems.

This information is useful for larger firms for faciliating internal knowledge-sharing; such firms may wish to consider their knowledge sharing goals and offer both online and in-person knowledge sharing opportunities for best results. It's also useful for firms with small technical teams. Our research suggests that software professionals feel their practice benefits from conversations with local peers, implying that smaller firms should consider how to support staff in meetup communities, perhaps from providing space for local groups, or examining how information can be shared safely for acquiring useful feedback.

The work outlined in this paper is preliminary only and reveals numerous areas for further study. Future work is needed to understand better the knowledge exchange mechanisms at meetups, and whether assumptions and lessons derived from one region are easily ported to other cities. This study only examines the positive factors that encourage participants to attend meetups; we have not examined the motivations and perspectives of practitioners who choose not to engage. It also not well understood yet the role that an active and lively meetup community can play in a regional technology sector - for example, by helping to growing a region's local skills pool, mentoring and supporting practitioners in key regional specialisms, or creating fertile ground for new startups.

\section{ACKNOWLEDGMENTS}

This work is funded by the Digital Creativity Labs jointly funded by EPSRC/AHRC/InnovateUK under grant EP/M023265/1. We extend our sincere thanks to all our interviewees and survey respondents for their time and inputs.

\section{REFERENCES}

[1] Lada A. Adamic, Jun Zhang, Eytan Bakshy, and Mark S. Ackerman. 2008. Knowledge sharing and Yahoo answers: everyone knows something. In $W W W$ '08: Proc. of the 17th Intl. Conf. on World Wide Web. ACM, New York, NY, USA, 665-674. 
[2] Hayward P. Andres. 2002. A comparison of face-to-face and virtual software development teams. Team Performance Management: An International fournal 8, $1 / 2$ (2002), $39-48$.

[3] Maurício Aniche, Christoph Treude, Igor Steinmacher, Igor Wiese, Gustavo Pinto, Margaret-Anne Storey, and Marco Aurélio Gerosa. 2018. How Modern News Aggregators Help Development Communities Shape and Share Knowledge. In 2018 40th International Conference on Software Engineering (ICSE). IEEE/ACM, 499-510. https://doi.org/10.1145/3180155.3180180

[4] Bjøørn Asheim. 2007. Differentiated Knowledge Bases and Varieties of Regional Innovation Systems. Innovation: The European fournal of Social Science Research 20 (2007), 223-241. Issue 3.

[5] Bjørn T. Asheim and Lars Coenen. 2005. Knowledge bases and regional innovation systems: Comparing Nordic clusters. Research Policy 34 (2005), 1173-1190.

[6] Bjørn T. Asheim, Lars Coenen, Jerker Moodysson, and J. Vang. 2007. Constructing knowledge-based regional advantage: implications for regional innovation policy. International fournal of Entrepreneurship and Innovation Management 7 (2007), 140-155.

[7] Innovation Mapping Team at NESTA. 2019. Innovation mapping now. Technical Report. Tech City and NESTA, Technical report [online] https://www.nesta.org. $\mathrm{uk} /$ report/innovation-mapping-now/.

[8] William T. Bielby and Denise D. Bielby. 1999. Organizational mediation of projectbased labor markets: talent agencies and the careers of screenwriters. American Sociological Review 64 (1999), 64-85.

[9] The Meetup Blog. 2015. Tech Meetups on the rise across America [Online] http://blog.meetup.com/tech-meetups-across-america/.

[10] Gargi Bougie, Jamie Starke, Margaret-Anne Storey, and Daniel M. German. 2011 Towards Understanding Twitter Use in Software Engineering: Preliminary Findings, Ongoing Challenges and Future Questions. In Proceedings of the 2nd International Workshop on Web 2.0 for Software Engineering. ACM, New York, NY, USA, 31-36.

[11] Mary Brandel. 2016. How to make tech meetups work for you. Technical Report. Computerworld [Online] https://www.computerworld.com/article/3064219/howto-make-tech-meetups-work-for-you.html.

[12] John Seely Brown and Paul Duguid. 1991. Organizational Learning and Communities-of-Practice: Toward a Unified View of Working, Learning, and Innovation. Organization Science 2, 1 (1991), 40-57.

[13] Yannis Caloghirou, Ioanna Kastelli, and Aggelos Tsakanikas. 2004. Internal capabilities and external knowledge sources: complements or substitutes for innovative performance? Technovation 24 (2004), 29-39.

[14] Richard E. Caves. 2000. Creative Industries: Contracts Between Art and Commerce. Harvard University Press, Cambridge, MA.

[15] John W. Creswell and Vicki L. Plano Clark. 2017. Designing and conducting mixed methods research. Sage, Thousand Oaks, CA.

[16] Juan Mateos Garcia and Hasan Bakhshi. 2016. The Geography of Creativity in the UK. Technical Report. NESTA and Creative England, [Online] https: //www.nesta.org.uk/report/the-geography-of-creativity-in-the-uk/.

[17] Juan Mateos Garcia and James Gardiner. 2016. From detecting to engaging: An analysis of emerging tech topics using Meetup data. Technical Report. NESTA, 27 July [Online] https://www.nesta.org.uk/blog/from-detecting-to-engaging-ananalysis-of-emerging-tech-topics-using-meetup-data/.

[18] Juan Mateos Garcia, Joel Klinger, and Konstantinos Stathoulopoulos. 2018. Creative Nation: How the creative industries are powering the UK's nations and regions. Technical Report. NESTA and the Creative Industries Council, [Online] https://www.nesta.org.uk/report/creative-nation/.

[19] Michael M. Gielnik, Michael Frese, Johanna M. Graf, and Anna Kampschulte. 2012. Creativity in the opportunity identification process and the moderating effect of diversity of information. Fournal of Business Venturing 27, 5 (2012), 559-576. https://doi.org/10.1016/j.jbusvent.2011.10.003

[20] G. Grabher. 2002. The project ecology of advertising: tasks, talents, and teams. Regional Studies 36 (2002), 245-262.

[21] Markus Grillitsch, Torben Schubert, and Martin Srholec. 2019. Knowledge base combinations and firm growth. Research Policy 48, 1 (2019), 234-247. https: //doi.org/10.1016/j.respol.2018.08.

[22] Tristan Handy. 2014. Who's Meeting Up? Using Data to Find the Hottest Startup Cities in the World. Technical Report.

[23] Andrea Hemetsberger and Christian Reinhardt. 2006. Learning and Knowledgebuilding in Open-source Communities: A Social-experiential Approach. Management Learning 37, 2 (2006), 187-214.

[24] Nola Hewitt-Dundas and Stephen Roper. 2018. Exploring market failures in open innovations. International Small Business fournal: Researching Entrepreneurship 36, 1 (2018), 23-40.

[25] Siw Elisabeth Hove and Bente Anda. 2005. Experiences from conducting semistructured interviews in empirical software engineering research. In 11th IEEE International Software Metrics Symposium (METRICS'05). 10 pp.-23. https://doi. org/10.1109/METRICS.2005.24

[26] Jeremy R. L. Howells. 2002. Tacit Knowledge, Innovation and Economic Geography. Urban Studies 39, 5-6 (2002), 871-884.
[27] Oliver Ibert. 2004. Projects and firms as discordant complements. Organizational learning within the Munich software ecology. Research Policy 33 (2004), 15291546.

[28] Claire Ingram and Anders Drachen. 2020. Appendices for: 'How Software Practitioners Use Informal Local Meetups to Share Software Engineering Knowledge'. Technical Report. University of York, http://dx.doi.org/10.6084/m9.figshare.11569434 DOI: $10.6084 / \mathrm{m} 9$. figshare.11569434.

[29] Prasert Kanawattanachai and Youngin Yoo. 2002. Dynamic nature of trust in virtual teams. The fournal of Strategic Information Systems 11, 3-4 (2002), 187-21.

[30] Oksana Koryak, Andy Lockett, James Hayton, Nicos Nicolaou, and Kevin Mole. 2018. Disentangling the antecedents of ambidexterity: Exploration and exploitation. Research Policy 47, 2 (2018), 413-427. https://doi.org/10.1016/j.respol.2018. 01.

[31] Masaaki Kotabe and K. Scott Swan. 1995. The Role of Strategic Alliances in High-Technology New Product Development. Strategic Management fournal 16, 8 (1995), 621-636.

[32] Christine T. Kydd and Diane L. Ferry. 1994. Managerial use of videoconferencing. Information and Management 27, 6 (1994), 369-75.

[33] Keld Laursen and Ammon Salter. 2006. Open for innovation: The Role of Openness in Explaining Innovation Performance Among UK Manufacturing Firms. Strategic Management fournal 27 (2006), 131-150.

[34] Jean Lave. 1991. Situating Learning in Communities of Practice. In Perspectives on Socially Shared Cognition, Lauren B. Resnick, J. M. Levine, and S. D. Teasley (Eds.). American Psychological Association, Washington D.C., Chapter 4, 63-82.

[35] Angela M Lee and Hsiang Iris Chyi. 2015. The rise of online news aggregators: Consumption and competition. International fournal on Media Management 17, 1 (2015), 3-24.

[36] J. David Lewis and Andrew Weigert. 1985. Trust as a social reality. Social Forces 63, 4 (1985).

[37] Xingjie Liu, Qi He, Yuanyuan Tian, Wang-Chien Lee, John McPherson, and Jiawei Han. 2012. Event-based social networks: linking the online and offline social worlds. In Proceedings of the 18th ACM SIGKDD international conference on Knowledge discovery and data mining. 1032-1040.

[38] Augusto Q. Macedo, Leandro B. Marinho, and Rodrygo L.T. Santos. 2015. ContextAware Event Recommendation in Event-based Social Networks. In Proceedings of the 9th ACM Conference on Recommender Systems.

[39] Roman Martin and Jerker Moodysson. 2011. Comparing knowledge bases: on the geography and organization of knowledge sourcing in the regional innovation system of Scania, Sweden. European Urban and Regional Studies 20, 2 (2011), $170-187$.

[40] Juan Mateos-Garcia. 2015. Using Meetup data to explore the UK digital tech landscape. Technical Report. NESTA, 12 May, [Online] https://www.nesta.org. $\mathrm{uk} / \mathrm{blog} / \mathrm{using}$-meetup-data-to-explore-the-uk-digital-tech-landscape/.

[41] Roger C. Mayer, James H. Davis, and F. David Schoorman. 1995. An integration model of organizational trust. The Academy of Management Review 20, 3 (1995), 709-734.

[42] Daniel J. McAllister. 1995. Affect- and cognition-based trust as foundations for interpersonal cooperation in organizations. Academy of Management fournal 38, 1 (1995), 24-59.

[43] Paul Miller and Kirsten Bound. 2011. The Startup Factories. Technical Report. NESTA: Making Innovation Flourish, Discussion paper [online] https://www. nesta.org.uk/report/the-startup-factories/.

[44] Jerker Moodysson and Ola Jonsson. 2007. Knowledge collaboration and proximity: The spatial organization of biotech innovation projects. European Urban and Regional Studies 14 (2007), 115-131.

[45] Ikujiro Nonaka and Noboru Konno. 1998. The Concept of "Ba": Building a Foundation for Knowledge Creation. California Management Review 40, 3 (1998), $40-54$.

[46] Nadina Osmani. 2018. How many tech meetups exist in the UK? Technical Report. 11 December, Tech Nation [Online] https://technation.io/news/report-2018-techmeetups/.

[47] Paul B. Paulus and Vincent R. Brown. 2007. Toward More Creative and Innovative Group Idea Generation: A Cognitive-Social-Motivational Perspective of Brainstorming. Social and Personality Psychology Compass 1, 1 (2007), 248-265.

[48] Fabrizio Perretti and Giacomo Negro. 2007. Mixing genres, matching people: a study in innovation and team composition in Hollywood. Fournal of Organizational Behavior 28 (2007), 563-586.

[49] Oliver Plum and Robert Hassink. 2011. Comparing knowledge networking in different knowledge bases in Germany. Papers in Regional Science 90, 2 (2011), 355-371.

[50] Oliver Plum and Robert Hassink. 2014. Knowledge bases, innovativeness and competitiveness in creative industries: the case of Hamburg's video game developers. Regional Studies, Regional Science 1, 1 (2014), 248-268.

[51] Aimilia Protogerou, Yannis Caloghirou, and Nicholas S. Vonortas. 2017. Determinants of young firms' innovative performance: Empirical evidence from Europe. Research Policy 46, 7 (2017), 1312-1326. https://doi.org/10.1016/j.respol.2017.05.

[52] John K. Rempel, John G. Holmes, and Mark P. Zanna. 1985. Trust in close relationships. Fournal of Personality \& Social Psychology 49 (1985), 95-112. Issue 
[53] Stephen Ricken, Louise Barkhuus, and Quentin Jones. 2017. Going Online to Meet Offline: Organizational Practices of Social Activities through Meetup. In Proceedings of the 8th International Conference on Communities and Technologies. ACM, Troyes, France.

[54] Catherine M. Ridings, David Gefen, and Bay Arinze. 2002. Some antecedents and effects of trust in virtual communities. Fournal of Strategic Information Systems 11 (2002), 271-295.

[55] Thomas H. Sander. 2005. E-associations? using technology to connect citizens: The case of Meetup.com. In Proceedings of the Annual Meeting of the American Political Science Association. Washington D.C.

[56] Allen J. Scott. 2000. The Cultural Economy of Cities; Essays on the Geography of Image-Producing Industries. Sage, London. 239-52 pages.

[57] Abhishek Sharma, Yuan Tian, and David Lo. 2015. What's Hot in Software Engineering Twitter Space?. In In Proceedings of the International Conference on Software Maintenance and Evolution. IEEE Computer Society, Washington, DC, USA, 541-545.

[58] Abhishek Sharma, Yuan Tian, Agus Sulistya, David Lo, and Aiko Fallas Yamashita 2018. Harnessing Twitter to support serendipitous learning of developers. In Proceedings of the 24th International Conference on Software Analysis, Evolution and Reengineering. IEEE Computer Society, Washington, DC, USA, 387-391.

[59] John Short, Ederyn Williams, and Bruce Christie. 1976. The Social Psychology of Telecommunication. John Wiley, New York, N.Y.

[60] Pao Siangliulue, Kenneth C. Arnold, Krzysztof Z. Gajos, and Steven P. Dow. 2015. Toward Collaborative Ideation at Scale: Leveraging Ideas from Others to Generate More Creative and Diverse Ideas. In Proceedings of the 18th ACM Conference on Computer Supported Cooperative Work \&\#38; Social Computing (Vancouver, BC, Canada) (CSCW'15). ACM, New York, NY, USA, 937-945. https: //doi.org/10.1145/2675133.2675239

[61] Leif Singer, Fernando Figueira Filho, and Margaret-Anne Storey. 2014. Software Engineering at the Speed of Light: How Developers Stay Current Using Twitter. In In Proceedings of the 36th International Conference on Software Engineering. ACM, New York, NY, USA, 211-221.

[62] Henri Egle Sorotos. 2018. Meetups: the hidden underwiring of UK tech. Technical Report. Tech Nation, June 11, [online] https://technation.io/news/tech-meetups/.

[63] Jörg Sydow and Udo Staber. 2002. The institutional embeddedness of project networks: the case of content production in German television. Regional Studies
36 (2002), 215-227.

[64] TechCity and NESTA. 2016. Tech Nation 2016: Transforming UK Industries. Technical Report. Tech City and NESTA, [online] https://technation.io/insights/technation-2016/.

[65] Yuan Tian, Palakorn Achananuparp, Ibrahim Nelman Lubis, David Lo, and EePeng Lim. 2012. What Does Software Engineering Community Microblog About? In In Proceedings of the 9thWorking Conference on Mining Software Repositories. IEEE Press, Piscataway, NJ, USA, 247-250.

[66] Christoph Treude, Ohad Barzilay, and Margaret-Anne Storey. 2011. How Do Programmers Ask and Answer Questions on the Web?. In In Proceedings of the 33rd International Conference on Software Engineering (NIER track). ACM, New York, NY, USA, 804-807.

[67] Michaela Trippl, Franz Tödtling, and Lukas Lengauer. 2009. Knowledge Sourcing Beyond Buzz and Pipelines: Evidence from the Vienna Software Sector. Economic Geography 85 (2009), 443-462.

[68] Haridimos Tsoukas. 2003. Do We Really Understand Tacit Knowledge? In The Blackwell Handbook of Organizational Learning and Knowledge Management, E.-S. Mark and M. A. Lyles (Eds.). Blackwell Publishing, Oxford, 410-27.

[69] Mathijs De Vaan, Ron Boschma, and Koen Frenken. 2013. Clustering and firm performance in project-based industries: the case of the global video game industry, 1972-2007. Fournal of Economic Geography 13 (2013), 965-991.

[70] Erwin van Tuijl and Luís Carvalho. 2014. Knowledge sourcing, knowledge bases, and the spatial organisation of car design. Environment and Planning A 46 (2014), 1966-1982.

[71] Erwin van Tuijl, Koen Dittrich, and Jan van der Borg. 2016. Upgrading of Symbolic and Synthetic Knowledge Bases: Evidence from the Chinese Automotive and Construction Industries. Industry and Innovation 23, 3 (2016), 276-293.

[72] Xiaofeng Wang, Ilona Kuzmickaja, Klaas-Jan Stol, Pekka Abrahamsson, and Brian Fitzgerald. 2014. Microblogging in Open Source Software Development: The Case of Drupal and Twitter. IEEE Software 31, 4 (2014), 72-80.

[73] YuWu, Jessica Kropczynski, Patrick C. Shih, and John M. Carroll. 2014. Exploring the Ecosystem of Software Developers on GitHub and Other Platforms. In In Proceedings of the Companion Publication of the 17th ACM Conference on Computer Supported Cooperative Work \& Social Computing. ACM, New York, NY, USA, 265-268. 